
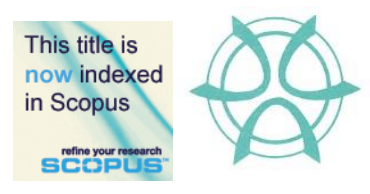

PLANNING MALAYSIA:

Journal of the Malaysian Institute of Planners

VOLUME 15 ISSUE 1 (2017), Page 109 - 116

\title{
FENG SHUI: THE SHAPE OF FIVE ELEMENTS OF LOW TI KOK MANSION
}

\author{
Chong Kai Zhen', \& Azizi Bahauddin² \\ ${ }^{1,2}$ School of Housing, Building, and Planning, \\ UNIVERSITI SAINS MALAYSIA
}

\begin{abstract}
Feng shui is one of the most outstanding subjects and popular life principles in the world and is also one of the oldest traditional Chinese philosophies. Feng shui is seen as wisdom that has been accumulating for more than three thousand years of history and experience in architectural theory. The application of feng shui is not only a unique knowledge but is also a complex way to comprehend natural phenomena. The aim of feng shui in architecture is to enhance the quality of life for humans, building, and nature. It is related to the built environment theory. Feng shui had indeed been incorporated into the construction of Chinese mansions in Peninsula Malaysia despite having only a few people who are aware of them. Since feng shui is a complex subject, this paper focuses on one of the feng shui principles: the Five Elements. The Five Elements and their respective shapes are Water, wavy-shaped; Wood, angular-shaped; Fire, triangle; Earth, square; and Metal, circle. These elements are discussed in their association with the case study of Low Ti Kok Mansion. The Low Ti Kok Mansion, which is located in Kajang, Selangor, has no recorded documentation on feng shui as opposed to the Cheong Fatt Tze Mansion in Penang, which is known for being influenced by feng shui. In this paper, the researcher attempts to investigate and document the case study based on feng shui influences. The objectives of this paper are twofold and they are (1) to understand the feng shui and (2) to examine the Five Elements concept on the Low Ti Kok Mansion. The research approach in this paper is qualitative in nature. Document reviewing and observation have been employed and interpreted in this paper to analyse the case study, which is based on the Five Elements concept. It is found that the Five Elements shapes are clearly shown on the floor plan of Low Ti Kok Mansion.
\end{abstract}

Keyword: Five Elements, feng shui, Low Ti Kok Mansion

Date Received: $30^{\text {th }}$ April 2016

Date of Acceptance: $30^{\text {th }}$ October 2016 
Chong Kai Zhen, \& Azizi Bahauddin

Feng Shui: The Shape of Five Elements of Low Ti Kok Mansion

\section{INTRODUCTION}

Feng shui is an ancient practice that has accumulated more than three thousand years of history, knowledge and experience. It has also been incorporated into architectural theory, especially with regards to position and design. Feng shui is a part of an ancient Chinese philosophy of nature and is considered a cultural heritage in China (Erdogan \& Erdogan, 2014). Since feng shui is considered a traditional Chinese philosophy and not a religion and belief, feng shui practice is popular among people. It has flourished worldwide when the literature about it in English was introduced (Erdogan \& Erdogan, 2014; Lip, 2010).

The practice of feng shui has also continued uninterrupted in fate and business among Chinese communities in Hong Kong, Taiwan, Malaysia, and Singapore (Lip, 1979). This basic purpose of feng shui is to enhance the quality of harmonious life between humans, buildings, and nature (Erdogan \& Erdogan, 2014).

The feng shui philosophy is a wide and complex subject in architecture theory. Unity of Heaven, Earth, and Human, qi, yin and yang principle, and the Five Elements are principles used in feng shui. These principles incorporate divination, medicine, and astrology. Feng shui also incorporates certain fields of science, especially climatology, geology, topography, ecology and landscaping. The architectural theory of feng shui can be divided into two main schools of thought: the Form School and Compass School (Yap, 2007). The Form School emphasises the consideration of earth surface where the $q i$, the energy, is affected while the Compass School focuses on the cosmic pattern, magnetic field, and sensitive direction based on the Chinese compass. The Form School has been widely accepted by international researchers in the analysis of built environment (Yap, 2007).

During the late nineteenth century, the Chinese migrants brought their culture including feng shui and architecture into Malaysia. Chinese builders incorporated feng shui into Chinese houses, especially shophouses and mansions. The Cheong Fatt Tze Mansion is an excellent example of a mansion in which feng shui has been strictly incorporated. The architectural aspect of feng shui had been used and it flourished in Chinese houses until the late 1930s.

Since feng shui is a complex subject, this paper focuses on one of its aspects, which is the Five Elements. This paper investigates the incorporation of the Five Elements into the construction of the Low Ti Kok Mansion in Kajang, which has no recorded documentation to date.

\section{LITERATURE REVIEW}

\section{Feng Shui}

The term of feng shui is extremely difficult to translate (Yap, 2007). Feng shui is a tool in designing and orientating the site to balance between human and nature. 
PLANNING MALAYSIA

Journal of the Malaysia Institute of Planners (2017)

It is a need to understand the relationship between the conditions of surrounding and humans. Feng shui might be called environmentology and is not related to Chinese geomancy. In definition, feng shui is the art of placing a building on a site so that it is in harmony with other man-made structures and in balance with nature (Erdogan \& Erdogan, 2014). Yap (2007) states that feng shui is a skill of studying the flow of invisible energy in the environment, planetary influences, and contours of the land, and river and mountain formations in relation to a property.

Feng shui is so deeply rooted in Chinese architecture that since historic times, it had been incorporated into architecture, environmental science, conceptual design, cultural heritage and interior decoration (Erdogan \& Erdogan, 2014). The art of feng shui has been accepted into architectural design principles in order to create sustainable buildings and environments (Mak \& So, 2015). It reflects nature and buildings. This concept of feng shui has been widely used in modern buildings in Hong Kong especially the Bank of China and Shanghai Bank. The concept of feng shui in buildings is to obtain the balance between nature and human behavioural impacts.

\section{Five Elements}

The Five Elements comprises the five basic groups of substances in the world. There are the elements of Wood, Fire, Earth, Metal, and Water. This theory of Five Elements represents the initiation, progress, development, fatigue, and cessation processes of events (Mak \& So, 2015). The Five Elements can be determined by the element of a people to obtain the suitable element after organising the interior space. Every space has its element of the Five Elements such as bathroom represents Water.

The Five Elements present their characteristics in seasons, times, directions, conditions, colours, forms, and numbers. The Five Elements have its cycle between two elements. For example, Water is related to the colour black while Fire is related to red. These elements are destroyed where Water will extinguish Fire according to a specific order. The cycles of the Five Elements are the productive cycle, controlling cycle, and weakening cycle (Lip, 2010). The productive cycle creates positive energy and produces the element. In other words, Fire produces Earth; Earth produces Metal; Metal produces Water; Water produces Wood; and finally Wood produces Fire. The controlling cycle creates negative energy and destroys the opposite element: Fire destroys Metal; Metal destroys Wood; Wood destroys Earth, Earth destroys Water; and Water destroys Fire. The weakening cycle creates the natural cycle between elements. The productive and controlling cycles are commonly used in the Five Elements. These cycles assist in creating the movement of energy in nature according to the laws of nature and heaven (Erdogan \& Erdogan, 2014). Figure 1 shows the three cycles of the Five Elements 


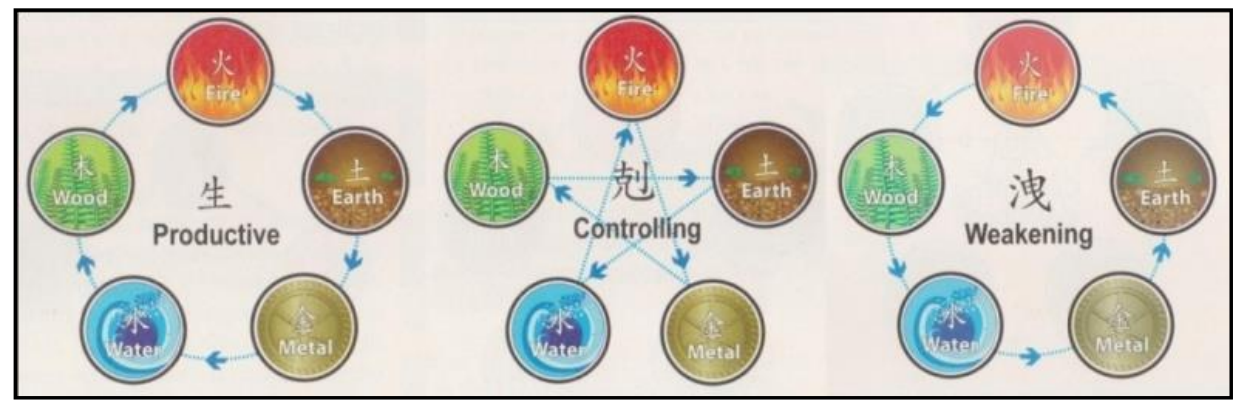

Figure 1 The Cycles of the Five Elements Source: Lip, 2010.

The shape of the Five Elements can be seen on the gable end wall of the Chinese shophouse. The pointed shape represents Fire, the square or flat shape, Earth, the round shape, metal, the wavy-shaped, Water, and angular-shaped is Wood. Figure 2 shows the shape of the Five Elements on the gable end wall.

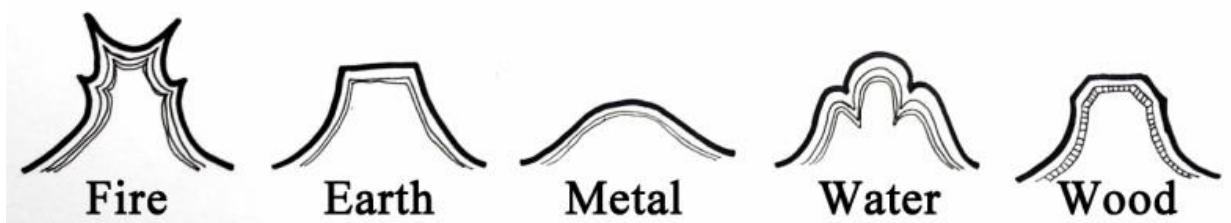

Figure 2 The Five Elements on the Gable End Wall. Source: Drawn by author from Tan.

\section{METHODOLOGY}

To investigate the Five Elements on the case study, the qualitative research approach is employed through observation. The primary sources such as visual data and the secondary sources are gathered. All information are then presented and interpreted in the findings of this paper.

\section{CASE STUDY}

The Low Ti Kok Mansion is located in the north of Kajang Town in Hulu Langat District. Historically, this mansion was built in 1932 and was owned by Towkay Low Ti Kok (1877-1943). This mansion was sold to the Hulu Langat Hokkien Association (HLHA) in 1985 and is known as HLHA building today. Today, it still stands as an old Chinese mansion that escaped the bombing during World War II in Kajang. Figure 3 shows the floor plan surveyed by researcher during fieldwork. 

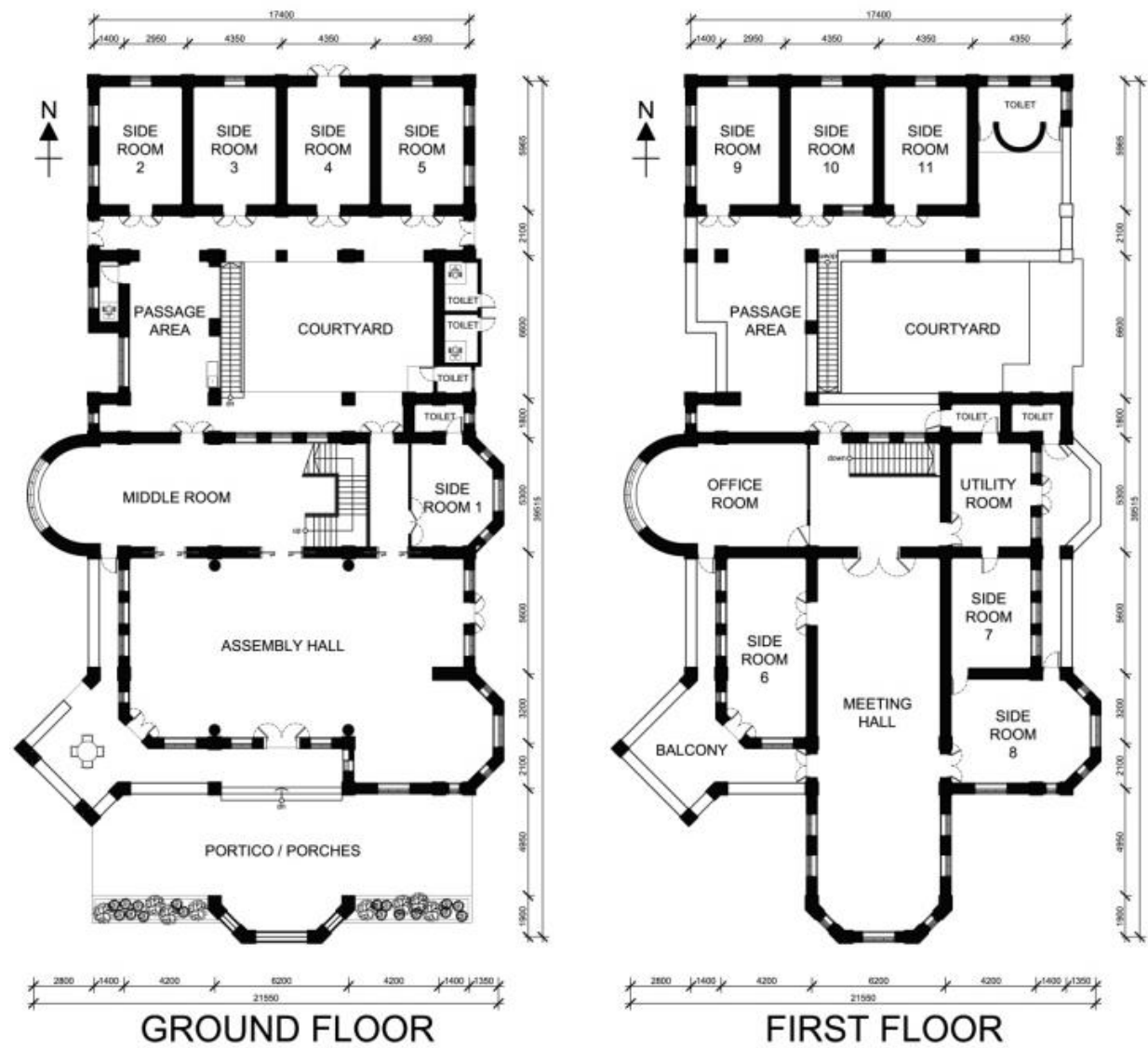

Figure 3 Floor Plan of Low Ti Kok Mansion Source: Adapted and surveyed by author

The Low Ti Kok Mansion is facing directly south. In Figure 3, it can be seen that there are different shapes such as semi-circle, angular-shape, and square, on the outline of the floor plan of the Low Ti Kok Mansion. The semi-circle and square can be seen on the right side of the mansion while angular-shaped can be seen at the front and the left side of the mansion. These shapes will be discussed in the findings of this paper to reveal the shape related to the Five Elements.

\section{FINDINGS}

This section discusses the findings of the Low Ti Kok Mansion based on the Five Elements. According to the Four Emblems, there is a Black Tortoise at the back; Green Dragon on the left; Red Bird in the front; and White Tiger on the right of the site. These Four Emblems are related to the Five Elements and the symbolism of the shapes. They are Black Tortoise represents Water and is wavy-shaped; The 
Chong Kai Zhen, \& Azizi Bahauddin

Feng Shui: The Shape of Five Elements of Low Ti Kok Mansion

Green Dragon is Wood and rectangular or angular-shaped; the Red Bird is Fire and triangular; and White Tiger is Metal and circular.

Besides that, according to the Nine Chambers of the Magic Square, the Five Elements are also related to direction. North is Water; Northeast and Southwest is Earth; East and Southeast is Wood; South is Fire; and Southwest and West is Metal. These elements are also represented by the shape.

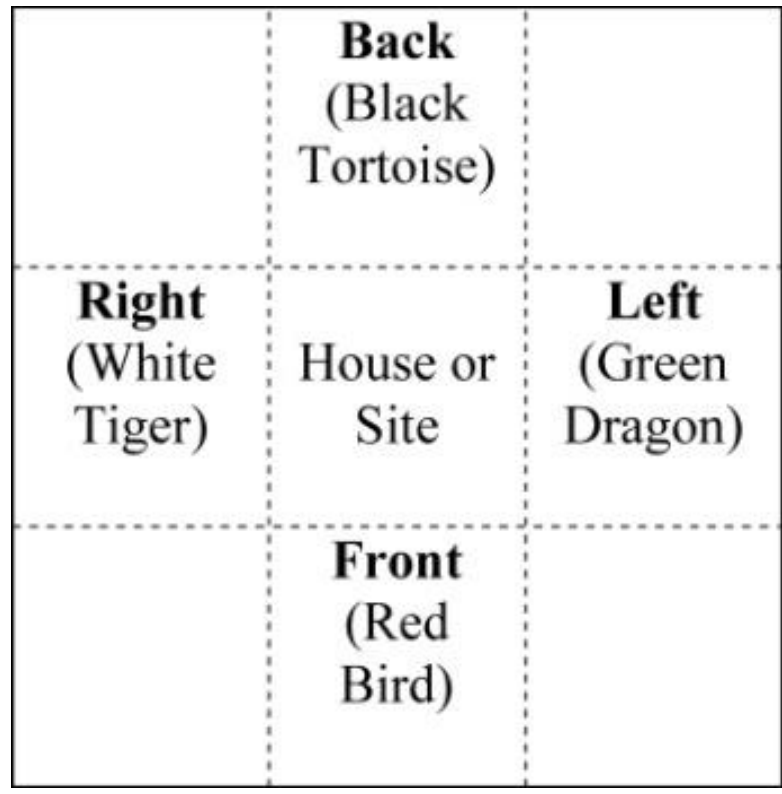

Figure 4 Four Emblems

Source: Modified by author

From the findings, it is found that the semi-circle at the right side of the Low Ti Kok Mansion has a similar concept to the Metal in the Five Elements of the Nine Chambers. The angular shape on the left side represents Wood while the square at the southwest is related to Earth. Besides that, the front of the mansion is angular-shaped which represents the Wood Element and it faces South, the Fire Element. According to the productive cycle of the Five Elements, this is preferable as Wood produces Fire. 
PLANNING MALAYSIA

Journal of the Malaysia Institute of Planners (2017)

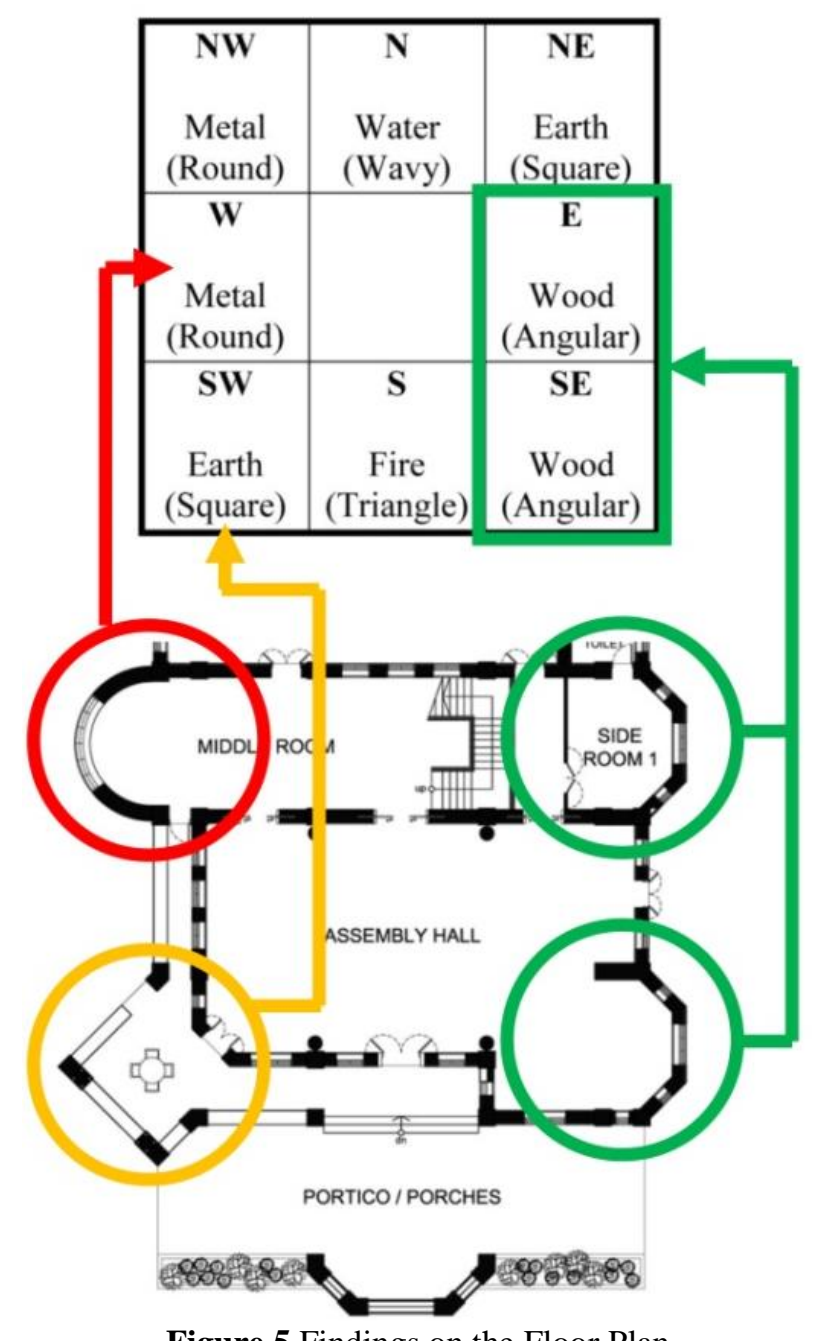

Figure 5 Findings on the Floor Plan Source: Modified by author

\section{CONCLUSIONS}

This study is not only crucial but is also enlightening for the understanding of the design of feng shui in architectural theory. Shapes are used by humans to design buildings. The shaping of the buildings has an impact on the building and surrounding nature. The main idea of this study is the application of the shapes of the Five Elements to reflect the design principles, especially of harmony and of balance. This can be used as a guide for designers in the feng shui concept. It assists in enhancing the concept of sustainability in nature and future architectural space. 
Chong Kai Zhen, \& Azizi Bahauddin

Feng Shui: The Shape of Five Elements of Low Ti Kok Mansion

\section{ACKNOWLEDGMENT}

The author thanks the support of USM Fellowship.

\section{REFERENCES}

Erdogan, E., \& Erdogan, H. A. (2014). Feng shui paradigm as philosophy of sustainable design. International Journal of Social, Behavioral, Educational, Economic, Business and Industrial Engineering, 8(10), 3328-3333.

Lip, E. (2010). All you need to know about feng shui. Singapore: Marshall Cavendish International (Asia) Private Limited

Lip, E. (1979). Chinese geomancy. Singapore: Times Books International

Yap, J. (2007). Xuan Kong flying stars feng shui: an introduction to flying stars feng shui. Kuala Lumpur: JY Books Sdn. Bhd.

Mak, M. Y., \& So, A. T. (2015). Scientific feng shui for the built environment: theories and applications. Hong Kong: City University of Hong Kong Press. 